\title{
METHODS OF SALIVATION REDUCTION ASSESSMENT AT A DENTAL APPOINTMENT
}

D0I: 10.36740/WLek202006136

\author{
Natalia A. Riabushko \\ UKRAINIAN MEDICAL STOMATOLOGICAL ACADEMY, POLTAVA, UKRAINE
}

\begin{abstract}
The aim: To develop and study the methods of assessing the decrease in salivation during a dental appointment.

Materials and methods: We formed an observation group of 185 people (61 men and 124 women), which complained of dry mouth.

Results: According to the results of the survey, we found that 10.3\% (19 patients) had moderate xerostomia and $89.7 \%$ (166 patients) had pronounced xerostomia. In 179 patients (96.8\%) with complaints of dry mouth and with a subjective assessment as pronounced xerostomia, salivation rate was, on average, $0.08 \pm 0.01 \mathrm{ml} / \mathrm{min}$. That was reliably objectified by laboratory indicator of hyposalivation - less than $0.1 \mathrm{ml} / \mathrm{min}$.

Conclusions: In our studies, we proved a direct relationship between patient complaints of dry mouth and laboratory-confirmed data. This makes it possible for a stomatologistto quickly identify this pathology, analyze it and choose the right treatment tactic during clinical appointment.
\end{abstract}

KEY WORDS: oral fluid, decreased salivation, xerostomia

Wiad Lek. 2020;73(6):1264-1266

\section{INTRODUCTION}

Saliva - the main fluid, the biological environment of the oral cavity, produced by many salivary glands, performs crucial role in maintaining the structural and functional balance in the oral cavity [1,2]. Oral fluid is actively involved in local immune responses, trophic processes, protection against bacterial infections, digestion, endocrine regulation, maintaining physiochemical oral homeostasis.

Some studies $[3,4,5]$ indicate that maintenance of the oral cavity homeostasis is ensured by quantitative and qualitative balance of the oral fluid components, which depends on the body general condition, the functional usefulness of the salivary glands, the hygienic state of the oral cavity and physiochemical characteristics of saliva. Many studies have convincingly proven that saliva is an indicator of the health and morbidity of not only the oral cavity, but also the whole body.

"Xerostomia" defined by Hutchinson in 1889 as a condition, caused by dry mouth. Bivona P.L. in 1998 described xerostomia as "a personal feeling in the oral cavity on the background of hyposalivation" [6]. Denisov A.B. (2003) defines xerostomia as a cumulative symptom of dryness in the oral cavity sensation associated with a change or cessation of the salivary glands secretion [7].

\section{THE AIM}

To develop and study methods for assessing the decrease in salivation at a dental appointment.

\section{MATERIALS AND METHODS}

The clinical data of the patients who complained of dry mouth in 2018-2020 were analyzed. We formed an observation group of 185 people (61 men and 124 women).

Criteria for inclusion in the study: complaints about the presence of dryness in the oral cavity, the age of patients notyounger than 30 and not older than 75 years; voluntary consent of the patient to participate in the research program.

\section{RESULTS AND DISCUSSION}

The observation group was dominated by women (67\%), less often by men (33\%), mainly $(72.5 \%)$ in the age groups of $50-59$ years $(46.6 \%)$ and $60-69$ years $(25.9 \%)$.

To assess the decrease in salivation in dental patients, we conducted an in-depth survey, clarified the nature of complaints of dry mouth, its duration during the day (constant, episodic, daytime, nightly, etc.), and collection of anamnestic data. Patient complaints were examined in chronological order: the onset of the first manifestations of the "dry mouth" symptomand the duration of its existence were revealed. Also we clarified whether complaints of dry mouth were symptoms of the disease. We clarified the possible causes that, according to the patient, contributed to the occurrence of dryness in the oral cavity. The causes of exacerbation (intensification) of dryness in the oral cavity were revealed. The nature of nutrition, the patient's attitude to oral hygiene, the presence of occupational hazards, bad habits (smoking), allergic reactions, concomitant and transferred diseases were revealed. 
To do this, we developed a table that consists of 10 statements, each of which has three possible answers (no, this is not so; sometimes; right), which the patient gives himself with the guidance of a dentist. Also, for the diagnosis and detection of dryness in the oral cavity, we carried out an in-depth analysis of the patient's complaints: the duration of dryness during the day (constant, episodic, night, etc.). Patient complaints were examined in chronological order: they showed the onset of the first manifestations and their duration. We determined the possible derivative causes that, according to the patient, caused the disease of the oral mucosa and the symptoms of dry mouth. The causes of exacerbation of xerostomia were shown, special attention was paid to a combination of complaints with a feeling of pain, burning and numbness of the oral mucosa. Attention was paid to the indirect detection of dryness in the cavity: a feeling of dryness during excitement, sleep, prolonged conversation, the inability to eat food without drinking water, the need for drinking water at night due to dryness in the oral cavity. Data were entered into the patient's questionnaire.

After analyzing the questionnaires that the patients werefilling out, we found that most patients noted dry mouth in the morning - 100\% (185 patients) and a dry mouth throughout the day $-97.8 \%$ (181 patients), and 174 respondents indicated that they drink water with food to facilitate swallowing and the fact that they have discomfort when chewing solid food. $89.5 \%$ patients noted the frequent need for water intake due to nighttime oral cavity dryness, and also complained of dry lips.

In the category of answers according to the "sometimes" criterion, complaints of discomfort during a conversation, due to dryness in the oral cavity and the need to wake up at night to drink water dominated. $30.8 \%$ (57 patients) gave negative answers (the category "not, this is not so") to the question that they constantly use lollipops or chewing gum to reduce dryness in the oral cavity.

To evaluate the results, we calculated the scores in patients with complaints of dryness in the cavity and found that $10.3 \%$ (19 patients) had moderate xerostomia and 89.7\% (166 patients) had pronounced xerostomia.

The second stage to confirm the subjective sensations of the patient is an objective examination. During its implementation, attention was focused on the clinical assessment of dry mouth and the condition of the oral mucosa. To confirm the data of an objective examination, we determined the secretory function by the rate of salivation flow (speed of salivation of unstimulated oral fluid), estimating the volume obtained per unit time. Given that during the day, the flow of saliva may vary significantly, the collection of oral fluid was performed in the clinic from 9.00 to 10.00 .

The oral fluid was collected according to the Navazesh technique, in which the oral fluid was collected on an empty stomach by draining it into a measuring cup for 5 minutes. 2 hours before the start of the procedure, patients were advised to refrain from chewing gum, drinking any food and drink other than water. To obtain reliable results, patients are advised, if possible, not to use drugs for 6-8 hours before the start of the examination.

The salivation rate was determined by the ratio of the obtained volume of oral fluid $(\mathrm{ml})$ to the regulated time ( $5 \mathrm{~min}$ ) for which it was obtained (normal $-0.12-0.16 \mathrm{ml} /$ $\mathrm{min}$ ). The presence of hyposalivation in patients is fixed at a salivation rate of less than $0.10 \mathrm{ml} / \mathrm{min}$.

In 179 patients (96.8\%) with complaints of dry mouth and with a subjective assessment as pronounced xerostomia, salivation rate was, on average, $0.08 \pm 0.01 \mathrm{ml} / \mathrm{min}$. That was reliably objectified by laboratory indicator of hyposalivation - less than $0.1 \mathrm{ml} / \mathrm{min}$.

At the dentist's appointment, patients very often complain of dry mouth and its consequences. At the same time, we see a catastrophically small number of publications on xerostomia and hyposalivation. In our opinion, this indicates an underestimation of the problem.

\section{CONCLUSIONS}

In our studies, we proved a direct relationship between patient complaints of dry mouth and laboratory-confirmed data. This makes it possible for a dentist at a clinical appointment to quickly identify this pathology, analyze and choose the right treatment tactic.

\section{REFERENCES}

1. Arkelyan M., Tambovtseva N., Arzukanyan A. Osnovnyie prichinyi i klinicheskie proyavleniya kserostomii [The main causes and clinical manifestations of xerostomia]. Rossiyskiy stomatologicheskiy zhurnal. 2016; 20(2):74-78. (In Russian).

2. Martin-Piedra M., Aguilar-Salvatiera A., Herrera D. et al. Effectiveness of a recent topical sialogogue in the management of drag-indused. J. Clip. Exp. Dent. 2011; 3 (4): 268-273.

3. Uspenskaya 0. Suhost v polosti rta: uchebnoe posobie [Dry Oral:Tutorial]. N.Novgorod: Izdatelstvo NGMA. 2007: 32 s. (in Russian).

4. Ryabushko N. Dvornik V. Osnovni etiologichni faktori viniknennya [Basic etiologichesky factors winnings xerostomy]. Ukrayinskiy stomatologichniy almanah. 2018; 4:78-80. (In Ukrainian).

5. Dvornik V., Riabushko N., Dvornik I. Vpliv ishemichnoyi hvorobi sertsya ta farmakoterapiyi tsogo zahvoryuvannya na tkanini porozhnini rota [Absorption of ischemic twig of the heart and pharmacotherapy of total seizure on the fabric of an empty company]. Aktualni problemi suchasnoyi meditsini: Visnik UMSA. 2014; 14,1(45): 119-123. (In Ukrainian).

6. Juras D., Lukac J., Cekic-Arambasin A. et al. Effects of low-level laser treatment on mouth dryness. Coll Antropol. 2010; 34:1039-43.

7. Denisov A. Slyuna i slyunnyie [Saliva and salivary glands]. Moskva: Izdatelstvo RAMN; 2006, 372 p. (In Russian).

The paper has been written within the research scientific work, carried out at the Department of Orthopedic Dentistry with Implantology "New technologies, new and improved dental materials for the rehabilitation of patients with pathology of the dental and maxillofacial system»; State registration number 0111 U006304.

ORCID and contributorship:

Natalia A. Riabushko - 0000-0002-3699-0291 A,D,C,D,E,F 


\section{Conflict of interest:}

The Author declare no conflict of interest.

\section{CORRESPONDING AUTHOR}

Natalia A. Riabushko

Ukrainian Medical Stomatological Academy

Shevchenko 23 str., 36011 Poltava, Ukraine

tel: +380500422564

e-mail: ryabushkon@gmail.com

Received: 05.03 .2020

Accepted: 08.05 .2020 